\title{
Humanin Rescues Cultured Rat Cortical Neurons from NMDA-Induced Toxicity Not by NMDA Receptor
}

\author{
Ai-Ling Cui, ${ }^{1}$ Jian-Zhong Li, ${ }^{2}$ Zhi-Bo Feng, ${ }^{1}$ Guo-Lin Ma, \\ Liang Gong, ${ }^{1}$ Chun-Ling $\mathrm{Li}^{1}{ }^{1} \mathrm{Ce}$ Zhang, ${ }^{4}$ and Kefeng $\mathrm{Li}^{5}$ \\ ${ }^{1}$ Key Laboratory of Tissue Regeneration of Henan Province, Xinxiang Medical College, Eastern Part of Jinsui Road, Xinxiang, \\ Henan 453003, China \\ ${ }^{2}$ Clinical Laboratory of Heji Hospital Affiliated to Changzhi Medical College, 271 East Taihang Road, Changzhi, \\ Shanxi 046000, China \\ ${ }^{3}$ Department of Radiology, China-Japan Friendship Hospital, Beijing 100029, China \\ ${ }^{4}$ Department of Physiology, Shanxi Medical University, No. 56 Xinjian Road, Taiyuan, Shanxi 030001, China \\ ${ }^{5}$ School of Medicine, University of California, San Diego (UCSD), San Diego, CA 92093, USA \\ Correspondence should be addressed to Guo-Lin Ma; maguolin1964@gmail.com
}

Received 14 January 2014; Revised 11 April 2014; Accepted 29 April 2014; Published 19 May 2014

Academic Editor: Alejandro Higuera-Matas

Copyright (C) 2014 Ai-Ling Cui et al. This is an open access article distributed under the Creative Commons Attribution License, which permits unrestricted use, distribution, and reproduction in any medium, provided the original work is properly cited.

\begin{abstract}
Excitatory neurotoxicity has been implicated in many pathological situations and there is no effective treatment available. Humanin is a 24-aa peptide cloned from the brain of patients with Alzheimer's disease (AD). In the present study, excitatory toxicity was induced by N-methyl-D-aspartate (NMDA) in primarily cultured rat cortical neurons. MTT assessment, lactate dehydrogenase (LDH) release, and calcein staining were employed to evaluate the protective activity of humanin on NMDA induced toxicity. The results suggested that NMDA $(100 \mu \mathrm{mol} / \mathrm{L}, 2.5 \mathrm{hr})$ triggered neuronal morphological changes, lactate dehydrogenase (LDH) release ( $166 \%$ of the control), reduction of cell viability (about $50 \%$ of the control), and the decrease of living cell density (about $50 \%$ of the control). When pretreated with humanin, the toxicity was suppressed. The living cells' density of humanin treated group was similar to that of control. The cell viability was attenuated dose-dependently $\left(\mathrm{IC}_{50}=0.132 \mathrm{nmol} / \mathrm{L}\right)$. The $\mathrm{LDH}$ release was also neutralized in a dose-dependent manner. In addition, the intracellular $\mathrm{Ca}^{2+}$ overloading triggered by NMDA reverted quickly and humanin could not inhibit it. These findings indicate that humanin can rescue cortical neurons from NMDA-induced toxicity in rat but not through interfering with NMDA receptor directly.
\end{abstract}

\section{Introduction}

Glutamate has been recognized as a major neurotransmitter and mediates excitatory synaptic transmission in the mammalian central nervous system. Prolonged stimulation with glutamate has been reported to cause neurological disorders [1]. Glutamate plays its roles after binding to the receptors. N-Methyl-D-aspartate (NMDA) receptors, a group of ionotropic receptors of glutamate, are believed to be the key factors to initiate glutamate-induced excitotoxicity $[2,3]$. As $\mathrm{Ca}^{2+}$ channels, the overactivation of NMDA receptors leads to the overload of $\mathrm{Ca}^{2+}$ in the neurons. Although intracellular $\mathrm{Ca}^{2+}$ is necessary for nervous physiological processes, $\mathrm{Ca}^{2+}$ overload triggers abnormal activation of $\mathrm{Ca}^{2+}$ dependent protease, mitochondrial dysfunction, and subsequent neuronal death, which is named excitatory neurotoxicity. Excitatory neurotoxicity has been reported to be involved in a variety of pathogenesis, such as stroke, traumatic brain injury, schizophrenia, Parkinson's disease, cerebral ischemia, and neurodegeneration [4-6]. NMDA receptor antagonists have been explored for many years as therapeutic agents for the treatment of neurological disorders such as stroke, epilepsy, pain, and Parkinson's disease. However, it has been discovered that many of these compounds can cause adverse behavioral effects and produce neurotoxicity $[4,7]$.

Humanin $(\mathrm{HN})$ is a 24 -aa peptide encoded by an identified gene cloned from occipital lobe of the patients with Alzheimer's disease (AD) in autopsy in 2001. It is considered 
as Alzheimer's disease-selective neuroprotective peptide [810]. However, HN does not inhibit other toxic insults to neurons such as the neurotoxicity triggered by Fas, etoposide [8], glutamate [9], and NMDA [11].

Although $\mathrm{HN}$ is firstly identified from human brain with Alzheimer's disease, several HN homologues have been discovered in other species of animals including rat, mouse, monkey, and nematode [11-13]. It has also been identified in other tissues besides brain including testis, colon, skeletal muscles, and human vascular walls [13-15]. The widespread of $\mathrm{HN}$ implies that its role is versatile other than just attenuating Alzheimer's disease-related insults. In support of this notion, several studies have been conducted to decipher the neuroprotective mechanism of $\mathrm{HN}$ at cellular and molecular level, (1) to elevate ATP level $[14,16],(2)$ to block apoptosis $[9,12,17$, 18 ], and (3) to interfere with intracellular $\mathrm{Ca}^{2+}$ accumulation $[19,20]$. The mechanism mentioned above is necessary for any cells to survive under any stresses, which implies that $\mathrm{HN}$ might play versatile protective roles against broad insults other than as an $\mathrm{AD}$-selective neuroprotective peptide.

In this study, in order to verify the versatile neuroprotective role of HN, we investigated the effect of HN on NMDA induced neurotoxicity. Our results showed that HN attenuated NMDA-induced neurotoxicity and rescued cultured rat cortical neurons. We also found that HN did not play its neuroprotective role by interfering NMDA receptor directly.

\section{Materials and Methods}

2.1. Primary Cerebral Cortical Neuron Culture. The study was based on primarily cultured cortical neurons from neonatal Wistar rat (P1-3). Briefly, the pups were decapitated and cerebral cortexes were isolated and immersed into ice-cold D-Hanks buffer containing (in $\mathrm{mM}$ ) $\mathrm{NaCl} 136.7, \mathrm{KCl} \mathrm{5.4,}$ $\mathrm{NaHCO}_{3} 4.2, \mathrm{KH}_{2} \mathrm{PO}_{4} 0.4, \mathrm{NaH}_{2} \mathrm{PO}_{4} 0.6$, glucose 5.6, and $\mathrm{pH}$ 7.4. To dissociate cortices into single cells, they were minced mechanically into grains at about $1 \mathrm{~mm}^{3}$. The minced cortices were then digested with trypsin $\left(0.03 \%, \mathrm{pH} 7.4,37^{\circ} \mathrm{C}\right.$, Sigma) for $1 \mathrm{~min}$, centrifuged at $2,500 \mathrm{rpm}$ for $5 \mathrm{~min}$ and then resuspended in Dulbecco's Modified Eagle's Medium (DMEM, Gibco) with fetal calf serum (FCS, Sigma) 20\% $(\mathrm{V} / \mathrm{V})$ and penicillin-streptomycin $100 \mathrm{U} / \mathrm{mL}$. Cortical cells were plated on poly-D-lysine coated 6 -well $(3 \mathrm{~mL})$ or 96 -well $(100 \mu \mathrm{L})$ plates (Costar) at $5 \times 10^{5}$ cells $/ \mathrm{mL}$. Cells on 6 -well plates with coverslips were used for calcein staining and $\mathrm{Ca}^{2+}$ instantaneous concentration. Cells without coverslips were used for the assay of lactate dehydrogenase $(\mathrm{LDH})$ release. Cells grown on 96-well plates were used for MTT assay. Cytosine arabinoside (Ara-C) (Sigma) $(10 \mu \mathrm{mol} / \mathrm{L})$ was added $24 \mathrm{hr}$ after cell plating to limit the proliferation of nonneuronal cells. The culture media were half-refreshed every 2 days. All experiments were performed at DIV9.

2.2. Experimental Groups. In this study, the cultured neurons were grouped as follows: (1) control group, cultured neurons only; (2) HN group, cultured neurons incubated with $\mathrm{HN}$
(10 $\mu \mathrm{mol} / \mathrm{L})$; (3) NMDA group, cultured neurons incubated with NMDA $(100 \mu \mathrm{mol} / \mathrm{L})$ and Glycine $(10 \mu \mathrm{mol} / \mathrm{L})$ for $2.5 \mathrm{hr}$; (4) MK-801 group, MK-801 $(10 \mu \mathrm{mol} / \mathrm{L})$ was added into NMDA group; (5) $\mathrm{NMDA}^{+}+\mathrm{HN}$ group, $\mathrm{HN}$ was added into NMDA treated cells to achieve the final concentration of $0.01 \mu \mathrm{mol} / \mathrm{L}, \quad 0.1 \mu \mathrm{mol} / \mathrm{L}, \quad 1 \mu \mathrm{mol} / \mathrm{L}, \quad 10 \mu \mathrm{mol} / \mathrm{L}$, and $100 \mu \mathrm{mol} / \mathrm{L}$.

2.3. Chemicals Treatment. Cortical neurons isolated from the pups were cultured for 8 days before chemical treatment. HN (Shanghai Shenggong, China) was administrated $16 \mathrm{~h}$ in advance before NMDA treatment. After being preincubated with or without $\mathrm{HN}$ as grouped, neurotoxicity was induced by the treatment of $100 \mu \mathrm{mol} / \mathrm{L}$ of NMDA as described [21]. Acute neurotoxic exposure (NMDA challenge) was achieved by removing culture medium from cultured neurons. Collected medium was filter-sterilized and stored for future analysis. To remove traces of growth medium, cells were washed three times with prewarmed Locke's buffer containing (in mM) $\mathrm{NaCl} 154, \mathrm{KCl} 5.6, \mathrm{NaHCO}_{3} 3.6, \mathrm{CaCl}_{2}$ 2.3, $\mathrm{MgCl}_{2}$ 1.2, glucose 5.6, HEPES 5, and $\mathrm{pH}$ 7.4. They were incubated for $2.5 \mathrm{hr}$ with either drug-free or neurotoxin-containing $\mathrm{Mg}^{2+}$ free Locke's buffer (NMDA and MK-801/HN were added at concentrations as mentioned above). The incubation was terminated by removal of drug-containing buffer, followed by washing with prewarmed drug-free Locke's buffer containing $1 \mathrm{mM} \mathrm{Mg}^{2+}$. Finally, cells were cultured in previously collected original culture medium. At $24 \mathrm{hr}$, cells on coverslips were subjected to the assay of calcein staining and intracellular $\mathrm{Ca}^{2+}$ concentration measurement. Cells on 96-well plates were used for MTT assay. The medium in 6-well plates without coverslips was collected for the measurement of $\mathrm{LDH}$ release.

2.4. MTT Assay. Methylthiazolyldiphenyl-tetrazolium bromide (MTT) assay is a method to evaluate cell viability by measuring the integrity of mitochondria of viable cells. The assay was performed $24 \mathrm{hr}$ after the NMDA treatment as described [22]. It was initiated by removing the old culture medium and adding MTT dissolved in serum-free culture medium (final concentration of $0.5 \mathrm{mg} / \mathrm{mL}$, Sigma). Following $4 \mathrm{hr}$ incubation at $37^{\circ} \mathrm{C}$, the medium was aspirated and $0.1 \mathrm{~mL}$ of dimethyl sulfoxide was added to lyse the cells and dissolve the formazan crystals. The absorbance was recorded at $490 \mathrm{~nm}$ in a microplate reader (Benchmark, Bio-Rad). Cell viability was expressed as percentage of the absorption in control group which is exposed to drug-free buffer (100\%).

2.5. Calcein Staining. Calcein-acetoxymethyl ester (calcein$\mathrm{AM}$ ) is a nonfluorescent highly lipophilic and cell membrane permeant compound, which can be converted by intracellular esterases into calcein, an anionic fluorescent form. Therefore, calcein-AM only stains viable cells and provides both morphological and functional information of viable cells under microscopy and fluorometry. In this experiment, calcein staining was performed as described [23]. In brief, at $24 \mathrm{~h}$ after NMDA exposure, cells were washed once in Locke's buffer and loaded with $5 \mu \mathrm{M}$ calcein-AM (Fluka) in Locke's 
buffer for $30 \mathrm{~min}$. The neurons were then fixed in $4 \%$ paraformaldehyde for $30 \mathrm{~min}$ and fluorescence was visualized under fluorescent microscope (Olympus BX51) using $488 \mathrm{~nm}$ excitation and $520 \mathrm{~nm}$ emission filters. Five to eight independent experiments were performed and 4-5 random 200x fields per coverslip were photographed in each observation. Cell numbers were counted in each field. The data was shown as the percentage of fluorescent cells in each group compared with control.

2.6. Determination of LDH Release. Cell damage was quantified by the measurement of LDH activity in the culture medium released from the damaged cells. In the experiment, the culture mediums of the 6 -well plates were collected at $24 \mathrm{~h}$ after NMDA exposure. The activity of LDH in the culture medium was measured as described by Koh and Choi [24]. The release values were expressed as the percentage compared with that of control group which was set as $100 \%$. The data presented were mean \pm SD for 5 to 8 independent experiments using different batches of cells.

2.7. Measurement of Intracellular $\mathrm{Ca}^{2+}$ Concentration. At DIV 8 , the cultured neurons on coverslips were given HN according to the experimental group. After $16 \mathrm{~h}$, all groups were washed 3 times in Locke's buffer. They were then loaded with Fluo 3/AM (Biotium, Hayward, USA) in Locke's buffer containing $5 \mu \mathrm{mol} / \mathrm{L}$ Fluo 3/AM away from light and incubated at $37^{\circ} \mathrm{C}$ for $40 \mathrm{~min}$. The neurons were then washed 3 times with D-Hanks and observed under confocal laser scanning microscope (CLSM, Leica TCS SP5 II). Strong single neuron in the field was enrolled to be the subject. $\mathrm{Ca}^{2+}$ dependent fluorescence intensity was measured at an excitation wavelength of $488 \mathrm{~nm}$ and an emission wavelength of $530 \mathrm{~nm}$. The parameter was set to PMT $850 \mathrm{~V}$ and $30 \%$ of the intensity. Dynamic changes of cytoplasmic $\mathrm{Ca}^{2+}$ were captured and recorded every $660 \mathrm{~ms}$ and total 300 successive measurements (for about $198 \mathrm{~s}$ ) were recorded for each subject. Five to ten neurons were measured in each group and the average intensity was regarded as the intracellular $\mathrm{Ca}^{2+}$ instantaneous concentration of each group.

2.8. Statistical Analysis. All data were expressed as the mean \pm SEM. Significance of difference between groups was tested using one-way analysis of variance (ANOVA) followed by post hoc Tukey's multiple comparison test. Pvalues less than 0.05 were considered to be significant.

\section{Results}

3.1. NMDA Induced Occurrence of the Morphological Changes of Cortical Neurons. To establish a model of excitatory neurotoxicity, we treated cultured neurons at DIV9 with NMDA and observed the morphological changes under phasecontrast light microscope. Neurons at control group adhered to the plate bottom with clear nucleus and stretched with many processes. NMDA $(100 \mu \mathrm{mol} / \mathrm{L})$ treatment for $2.5 \mathrm{hr}$ induced the retraction of processes (Figure 1(b)). Subsequently, neurons turn round and their classical morphological characteristics disappeared (Figure 1(a)). Later, thick particles could be discerned in the damaged cells (Figure 1(c)) and then the bodies were burst into pieces. The remnant could still be seen in the picture (Figure 1(c)). The changes of cell morphology indicated the successful induction of excitatory neurotoxicity by $100 \mu \mathrm{mol} / \mathrm{L}$ of NMDA.

\subsection{Humanin Blocked the Reduction of Living Neurons Evoked} by NMDA. Calcein staining was employed to evaluate the density of living neurons. NMDA $(100 \mu \mathrm{mol} / \mathrm{L}, 2.5 \mathrm{hr})$ induced a significant decrease of living neurons in NMDA group. About half of the cells died. MK-801 is a noncompetitive antagonist of NMDA receptor. In MK-801 group, the density of living neurons was similar to the control which indicated that the toxicity was induced by NMDA. There was no statistical difference on the density of living neurons between $\mathrm{HN}$ group and control group, suggesting that $\mathrm{HN}$ $(100 \mu \mathrm{mol} / \mathrm{L})$ could mimic the function of MK-801 in blocking neuron toxicity triggered by NMDA (see Figure 2).

\subsection{Humanin Restored Cell Viability Decreased by NMDA} Treatment. NMDA $(100 \mu \mathrm{mol} / \mathrm{L}, 2.5 \mathrm{hr})$ was toxic to cortical neurons and caused the decrease of cell viability to $50 \%$ of the control as measured by MTT (Figure 3). The cell viability of MK-801 group was similar to that in control, which confirmed that the toxicity was evoked by NMDA. HN itself in the medium did not inhibit the cell viability. The cell viability was recovered by the addition of $\mathrm{HN}$ in NMDA treatment group. When the concentration of $\mathrm{HN}$ reached $0.1 \mu \mathrm{mol} / \mathrm{L}$, the decrease of cell viability began to be attenuated in NMDA treatment group. Ninety-eight percentage of the cell viability was recovered when $10 \mu \mathrm{mol} / \mathrm{L}$ of $\mathrm{HN}$ was added. Our results indicated that HN attenuated NMDAinduced insults effectively and dose-dependently $\left(\mathrm{IC}_{50}\right.$ was $0.132 \mu \mathrm{mol} / \mathrm{L}$ ).

3.4. Humanin Reduced the Release of LDH Triggered by NMDA. Our results showed that NMDA treatment $(100 \mu \mathrm{mol} / \mathrm{L}, 2.5 \mathrm{hr})$ caused the damage of cultured neurons and thus triggered the overrelease of LDH (Figure 4). LDH concentration in NMDA treatment group was about 1.66-fold higher than that in the control. MK-801 is a noncompetitive antagonist of NMDA receptor. As shown in Figure 4, the addition of MK-801 significantly reduced the release of $\mathrm{LDH}$ in NMDA treated neurons. The effect of $\mathrm{HN}$ is similar to MK801. Our results demonstrated that HN itself had no effect on normal neurons. However, the release of LDH was significantly inhibited in NMDA treated cells when the neurons were pretreated with $\mathrm{HN}$ for $16 \mathrm{~h}$. The concentration of $\mathrm{LDH}$ was about $135 \%$ of the control when $1 \mu \mathrm{mol} / \mathrm{L}$ of $\mathrm{HN}$ was added. No additional effect, however, could be detected when the concentration of $\mathrm{HN}$ continuously increased, even reached $100 \mu \mathrm{mol} / \mathrm{L}$.

3.5. HN Inhibited the Increase of Cytoplasmic $\mathrm{Ca}^{2+}$ Concentration Induced by NMDA. Our results showed that NMDA 

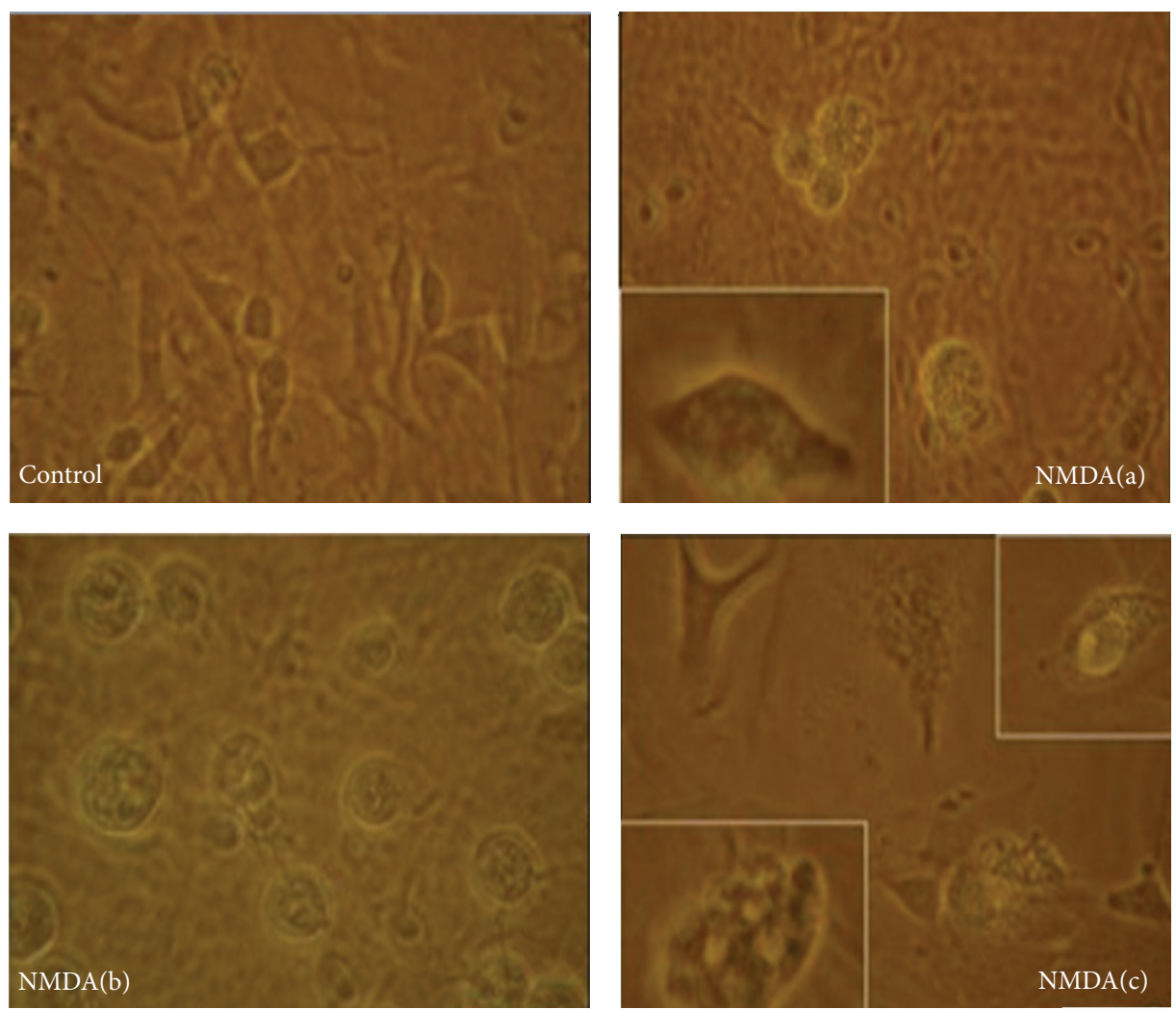

FIGURE 1: Morphological changes of cortical neurons induced by NMDA. Representative images of control and NMDA-treated cortical neurons $(\mathrm{a}, \mathrm{b}$, and $\mathrm{c}$ ) were observed under phase-contrast light microscope.
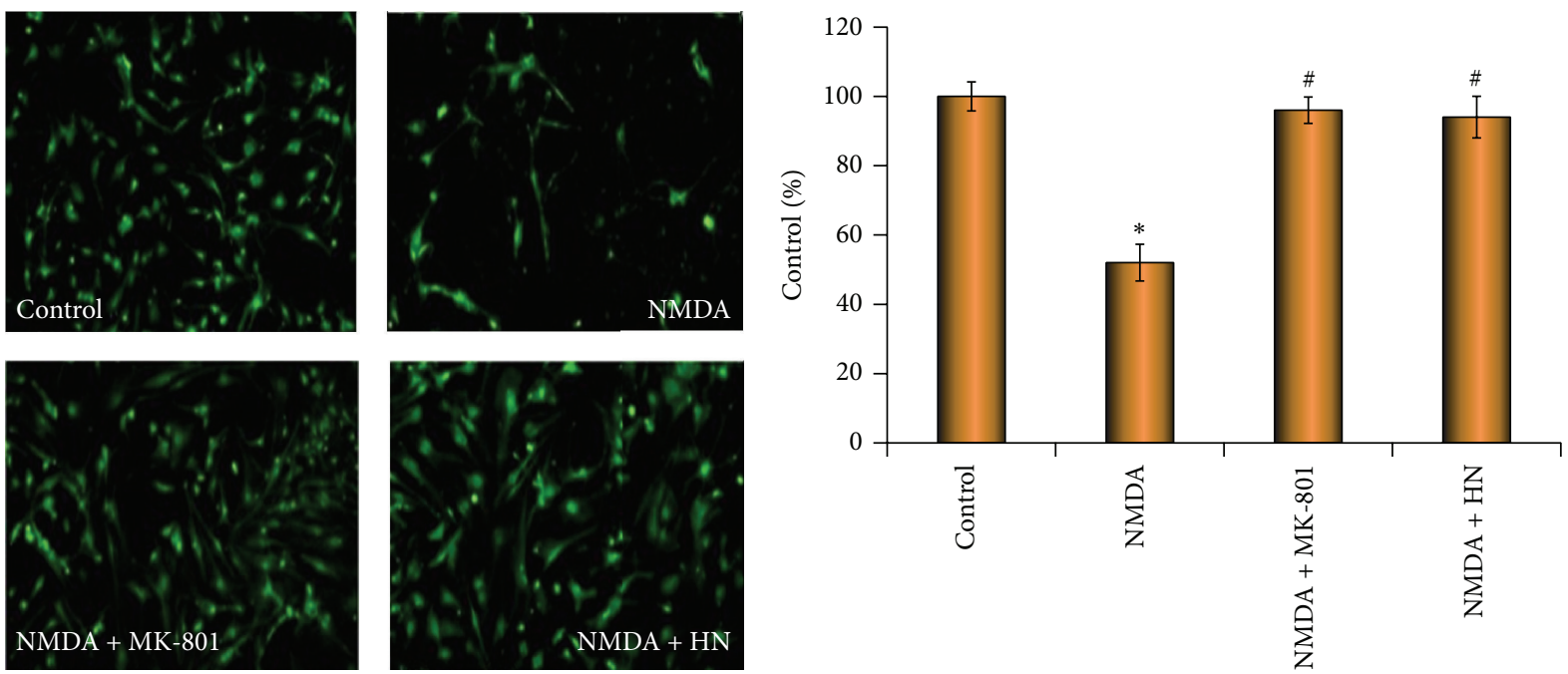

(a)

(b)

FIGURE 2: Effect of humanin on density of living neurons under the challenge of NMDA. Representative cellular density of each group is shown by calcein staining under fluorescence microscope. Each bar represents mean \pm SEM of eight independent observations. The date from each observation is expressed as the percentage of fluorescent cells in each group compared with control (100\%). Statistical significance is at $P<0.05 . F_{(3,116)}=4.826$ and $P=0.003$ according to one-way ANOVA analysis. $*$ represents control versus NMDA group, $P=0.012$; \# represents NMDA group versus NMDA + MK-801 group $(P=0.026)$ or NMDA + HN (Humanin) group $(P=0.009)$. * and \# mean the existence of statistical significance between. 


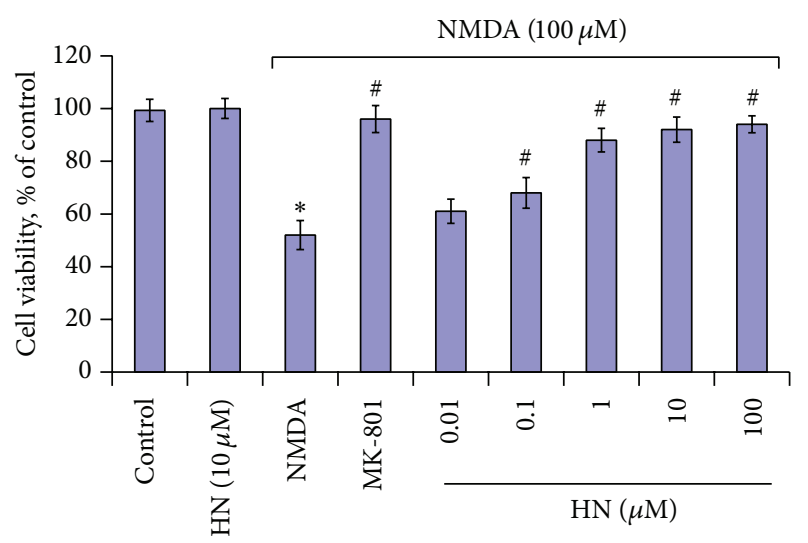

FIGURE 3: Effect of humanin on NMDA triggered reduction of cell viability in cortical neurons as measured by MTT cell viability assay. Each bar represents mean \pm SEM of five independent observations. Statistical significance is at $P<0.05 . F_{(8,64)}=2.697$ and $P=0.013$ according to one-way ANOVA analysis. * represents control versus NMDA group $(P=0.032)$; control versus $\mathrm{HN}(10 \mu \mathrm{mol} / \mathrm{L}), P=$ 0.421 ; \# represents NMDA group versus NMDA + MK-801 group $(P=0.026)$ or NMDA + HN (Humanin) group. HN $(0.01 \mu \mathrm{mol} / \mathrm{L})$, $P=0.289 ; \mathrm{HN}(0.1 \mu \mathrm{mol} / \mathrm{L}), P=0.036 ; \mathrm{HN}(1 \mu \mathrm{mol} / \mathrm{L}), P=0.024$; $\mathrm{HN}(10 \mu \mathrm{mol} / \mathrm{L}), P=0.012 ; \mathrm{HN}(100 \mu \mathrm{mol} / \mathrm{L}), P=0.021 . *$ and \# mean that there is statistical significance between control and treatment groups.

$(100 \mu \mathrm{mol} / \mathrm{L})$ triggered the rapid increase of cytoplasmic $\mathrm{Ca}^{2+}$ concentration and stayed at the highest level during the observation (Figure 5(a)). It only took $2 \mathrm{~s}$ for the increase of cytoplasmic $\mathrm{Ca}^{2+}$ concentration from the base level (60) to the peak value $(160)$. $\mathrm{HN}(0.1 \mu \mathrm{mol} / \mathrm{L})$ had no effect on interfering with NMDA-induced increase of cytoplasmic $\mathrm{Ca}^{2+}$ concentration. Although $\mathrm{HN}(1 \mu \mathrm{mol} / \mathrm{L})$ did not block the increase of cytoplasmic $\mathrm{Ca}^{2+}$ concentration induced by NMDA, it caused the gradual decrease of $\mathrm{Ca}^{2+}$ concentration from the peak value (180) to the control level (60) and even lower than the control (20) within $110 \mathrm{~s}$.

\section{Discussion}

Excitotoxicity is a leading cause of neurodegeneration observed in progressive and acute brain diseases. Despite many years search for effective neuroprotectants, there is still no effective therapy [25]. Humanin was cloned and identified from an apparently normal region of brain with Alzheimer's disease in 2001 and was considered as Alzheimer's diseaseselective neuroprotective peptide. But its wide location and the neuroprotective mechanism underlying suggests it to be versatile other than Alzheimer's disease-selective. Moreover, $\mathrm{HN}$ is encoded, transcribed, synthesized, and secreted from the occipital lobe of human brain. Therefore, $\mathrm{HN}$ might be a promising candidate in the therapy of excitatory neurotoxicity. Based on the consideration mentioned above, the possible neuroprotective role of $\mathrm{HN}$ against excitatory neurotoxicity was reverified in our experiment. In this study, the cytotoxicity of NMDA was quantified by measuring the activity of LDH released from the cultured neurons into the medium,

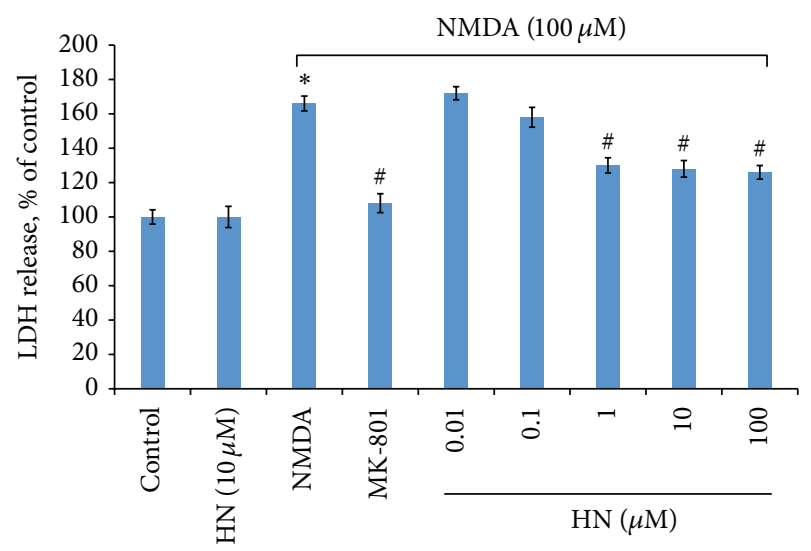

FIGURE 4: Effect of humanin on NMDA triggered LDH release in cultured cortical neurons. Each bar represents mean \pm SEM of 58 independent observations. Statistical significance is at $P<0.05$. $F_{(8,64)}=3.023$ and $P=0.006$ after one-way ANOVA analysis in SPSS. * represents control versus NMDA group $(P=0.028)$; \# represents NMDA group versus NMDA + MK-801 group $(P=$ $0.019)$ or NMDA + HN (Humanin) group. $\mathrm{HN}(0.01 \mu \mathrm{mol} / \mathrm{L}), P=$ 0.384 ; HN $(0.1 \mu \mathrm{mol} / \mathrm{L}), P=0.301 ; \mathrm{HN}(1 \mu \mathrm{mol} / \mathrm{L}), P=0.039 ; \mathrm{HN}$ $(10 \mu \mathrm{mol} / \mathrm{L}), P=0.036 ; \mathrm{HN}(100 \mu \mathrm{mol} / \mathrm{L}), P=0.040 . *$ and $\#$ mean that there is statistical significance between control and treatment groups.

and neuronal survival was quantified spectrophotometrically using MTT. The density of living cells was evaluated by calcein staining. Our results showed that NMDA caused the significant decrease of cell viability of cortical neurons. The addition of HN could, however, attenuate NMDA induced toxicity and increase the cell viability efficiently and dosedependently. The $\mathrm{IC}_{50}$ was $132 \mathrm{nmol} / \mathrm{L}$, a much lower concentration compared with that to neutralize Alzheimer's diseaserelated toxicity [9].

The result was confirmed by calcein staining. NMDAinduced toxicity triggered much more neuronal death in NMDA group. However, $\mathrm{HN}$ addition protected the neurons from NMDA-induced cell death. Additionally, NMDA evoked neuronal death and subsequent overrelease of LDH into medium. HN could neutralize the toxicity and reduced the release of LDH although it could not completely block the release.

The cytoprotective function of $\mathrm{HN}$ on excitatory neurotoxicity has ever been investigated by two laboratories by far. However, no protective effect was detected in either glutamate-induced [9] or NMDA-triggered [11] neuronal cell loss, which is different from what we have discovered in this study. The difference can be interpreted at least in part by the different experimental models. (1) The toxicity induced was different. In our experiment, the neurotoxicity was caused by NMDA while in Hashimoto's was by glutamate. Although the toxic agent in Caricasole's experiment and ours were the same even at the same dose (NMDA $100 \mu \mathrm{mol} / \mathrm{L})$, but the period cortical neurons exposed to the toxic agent was different (ours for $2.5 \mathrm{hr}$ versus Caricasole's for $10 \mathrm{~min}$ ). As toxicant, the longer the neurons were treated, the severer the damage it might have to the neurons; (2) HN was added to the medium 


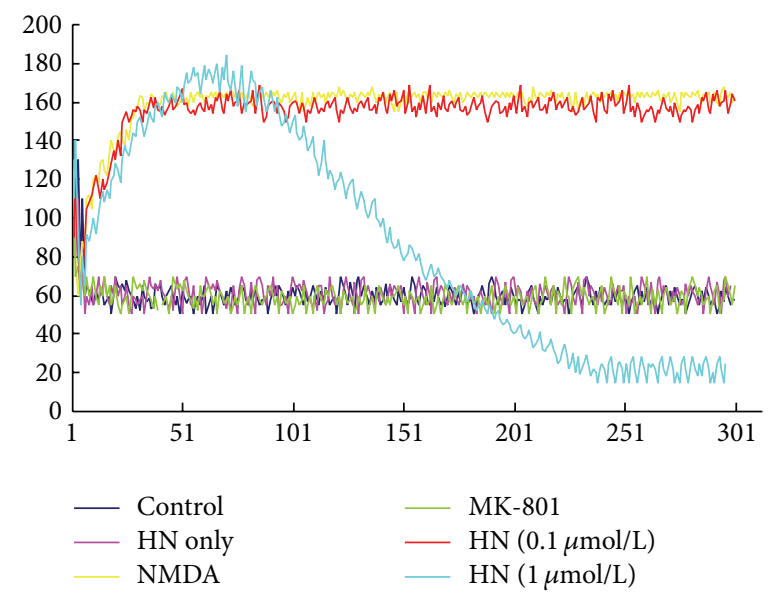

(a)
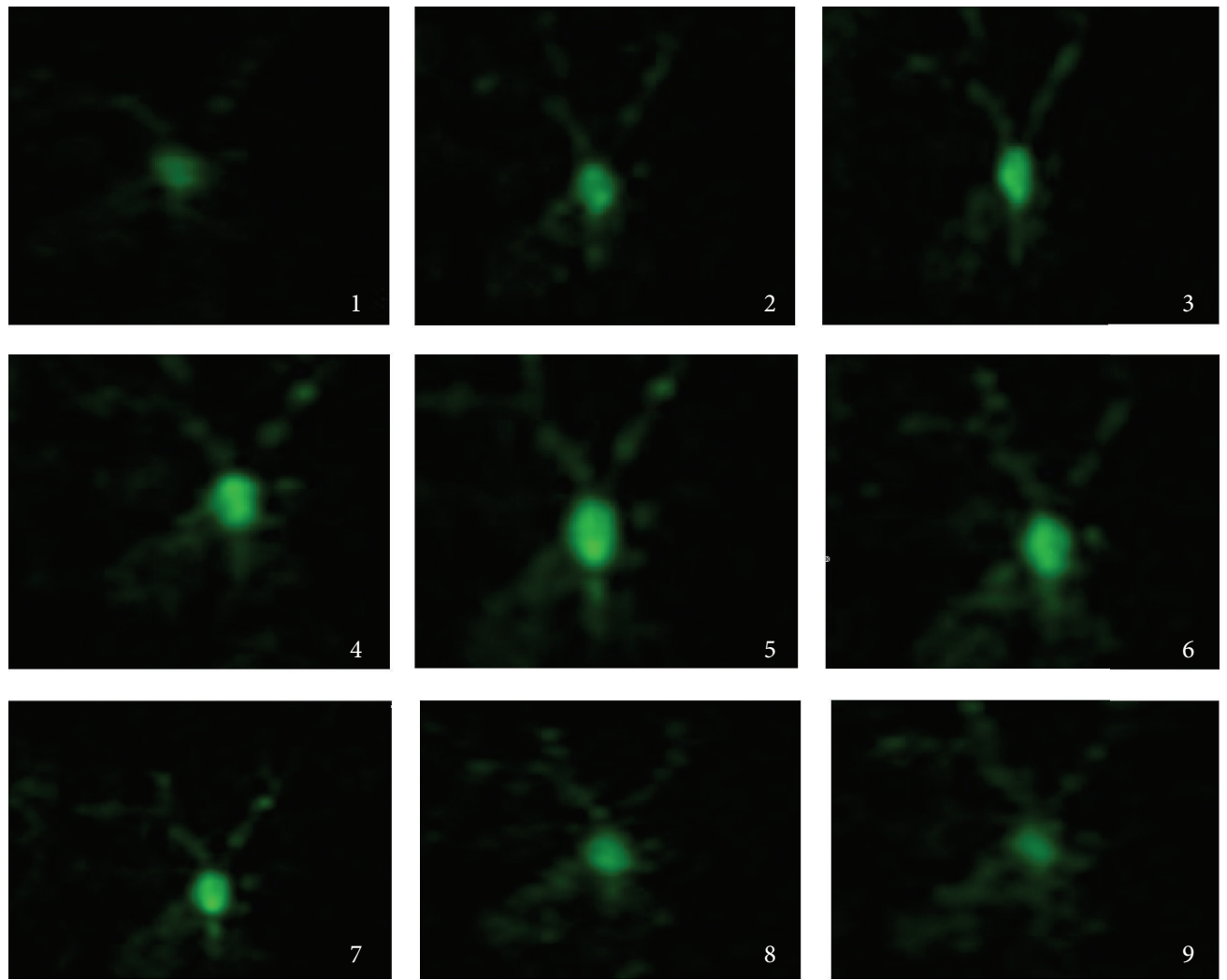

(b)

FIGURE 5: (a) Effect of humanin on NMDA triggered dynamic changes of cytoplasmic $\mathrm{Ca}^{2+}$ concentration. The fluorescence intensity which is related to cytoplasmic $\mathrm{Ca}^{2+}$ concentration was captured and recorded every $660 \mathrm{~ms}$ for 300 successive measurements (for about $198 \mathrm{~s}$ ) for each subject. 5 to 10 neurons were measured in every group. The curves are formed by the connection of 300 data which stand for the average instantaneous fluorescence intensity of each group. $\mathrm{HN}$ only: the addition of $10 \mu \mathrm{M} \mathrm{HN}$ itself in the medium. $\mathrm{HN}(0.1 \mu \mathrm{mol} / \mathrm{L})$ and $\mathrm{HN}(1 \mu \mathrm{mol} / \mathrm{L})$ groups: $\mathrm{HN}(0.1 \mu \mathrm{mol} / \mathrm{L})$ or $\mathrm{HN}(1 \mu \mathrm{mol} / \mathrm{L})$ in NMDA treatment groups. (b) Effect of humanin on NMDA triggered dynamic changes of cytoplasmic $\mathrm{Ca}^{2+}$ concentration. Picture 1 to picture 9 stand for the typical successive cellular morphological characteristics of $\mathrm{HN}$ $(1 \mu \mathrm{mol} / \mathrm{L})$ on NMDA-triggered increase of cytoplasmic $\mathrm{Ca}^{2+}$ concentration.

$16 \mathrm{~h}$ before the exposure of NMDA in our experiment. In Caricasole's study, HN was added $20 \mathrm{~h}$ after NMDA treatment (after exposure). The molecular mechanisms of the interaction between humanin and the neuron cells have not been completely understood. It is possible that the pretreatment of humanin activated the antioxidative defense system of the cells and thus protected the cells from NMDA stress [26]. (3) Different assay methods were employed. The toxicity was evaluated by MTT, LDH release, and calcein staining in our experiment, while trypan blue staining was employed to 
examine the neuronal death in the other two laboratories. Trypan blue can accumulate slowly in living cells and cause the cytotoxicity. The cell viability rate evaluated by trypan blue is usually lower than the real viable cell number.

In our experiment, the results suggested that $\mathrm{HN}$ was effective in attenuating NMDA-induced toxicity. But there was difference in effective concentration in the three methods. Because MTT assay is based on succinate dehydrogenase located in mitochondria, it could be positively detected even if the cell membrane was slightly broken. When the neuron cell membrane was completely broken, both MTT and LDH release could be positively detected. Humanin $(10 \mu \mathrm{mol} / \mathrm{L})$ could simulate the action of MK-801 and most recovered cell viability in MTT measurement. However, in the detection of LDH release, humanin could not inhibit the toxicity completely, even the concentration reached $100 \mu \mathrm{mol} / \mathrm{L}$. In calcein staining, the activity of intracellular esterases was measured. The results were consistent with MTT assay. Each method has its own advantages and disadvantages. It is necessary to evaluate the effect of $\mathrm{HN}$ based on the results of several different methods to avoid the limitations of each assay.

Since the toxicity was induced by NMDA in the experiment, overactivation of NMDA receptor and subsequent $\mathrm{Ca}^{2+}$ overloading is the toxic resource. How did Humanin interfere with $\mathrm{Ca}^{2+}$ overloading? To answer this quest, we measured intracellular $\mathrm{Ca}^{2+}$ instantaneous concentration and found that $\mathrm{HN}$ could not inhibit intracellular $\mathrm{Ca}^{2+}$ overloading triggered by NMDA. However, it could induce the reverting quickly, suggesting that $\mathrm{HN}$ attenuated NMDA-induced toxicity not by interfering with NMDA receptor directly. Further study on the expression of calcium handing proteins is needed to confirm the role of $\mathrm{HN}$ in calcium dynamics.

It was reported that $\mathrm{HN}$ mediates its protective effect by three putative receptors. Cytosolic $\mathrm{HN}$ partly inhibits staurosporine-induced cell death by binding to Bax and neutralizing the Bax-mediated proapoptotic pathway [12]. Secreted HN binds to cell-surface formyl peptide receptorlike-1 and a cell-surface receptor that belongs to the interleukin- (IL-) 6 receptor family to inhibit $\mathrm{A} \beta$-induced death of PC12 neuronal cells [27]. It is likely that the addition of $\mathrm{HN}$ into the medium will perform the similar role as the secreted $\mathrm{HN}$. In $\mathrm{MTT}$ assessment, $\mathrm{IC}_{50}$ of $\mathrm{HN}$ against NMDA-induced toxicity is about $0.1 \mu \mathrm{mol} / \mathrm{L}$ that is much lower than that of Humanin's protection in the death systems (1-10 $\mu \mathrm{mol} / \mathrm{L})$ mentioned above. This difference suggested that HN's receptor mediating the $\mathrm{HN}$-induced protection against NMDA toxicity to rat cortical neurons is different from the receptor that has been reported in the earlier studies. Attention should be paid to unveil the mechanism underlying before HN could be applied to clinic.

It was reported that $\mathrm{HN}$ increased the metabolic rate and the level of ATP in the cells $[14,15]$. HN is also expressed in human vascular walls and had a cytoprotective effect against oxidized LDL-induced oxidative stress [26]. Since MTT assessment is based on the activity of mitochondrial dehydrogenases, HN might protect the neurons from NMDAinduced toxicity by promoting the efficiency of mitochondria. A healthier mitochondrion could afford much more power to recover the elevated cytosolic $\mathrm{Ca}^{2+}$ concentration. Mitochondria dysfunction is the common characteristic when living cell is under insults. Promoting the efficiency of mitochondria may at least in part interpret the wide location of $\mathrm{HN}$ if it is the truth.

\section{Conclusion}

In this study, we employed NMDA induced toxicity as a model of excitatory neurotoxicity to explore the neuroprotective potential of humanin. We found that humanin rescued cortical neurons from NMDA-evoked toxicity effectively in rat in a dose-dependent manner. Our results indicated that humanin was not a specific neuroprotective peptide against Alzheimer's disease. It has broad neuroprotective activities. Our research thus sheds light on the therapy of excitatory neurotoxicity by supporting humanin as a promising candidate. Attention should be paid to unveil the mechanism underlying before humanin could be applied to clinic.

\section{Conflict of Interests}

The authors declare that there is no conflict of interests regarding the publication of this paper.

\section{References}

[1] D. W. Choi, "Glutamate neurotoxicity and diseases of the nervous system," Neuron, vol. 1, no. 8, pp. 623-634, 1988.

[2] C. G. Parsons, A. Stöffler, and W. Danysz, "Memantine: a NMDA receptor antagonist that improves memory by restoration of homeostasis in the glutamatergic system-too little activation is bad, too much is even worse," Neuropharmacology, vol. 53, no. 6, pp. 699-723, 2007.

[3] A. S. Ahmad, H. Zhuang, and S. Doré, "Heme oxygenase-1 protects brain from acute excitotoxicity," Neuroscience, vol. 141, no. 4, pp. 1703-1708, 2006.

[4] Ł. Dobrek and P. Thor, "Glutamate NMDA receptors in pathophysiology and pharmacotherapy of selected nervous system diseases," Postepy Higieny i Medycyny Doswiadczalnej, vol. 65, pp. 338-346, 2011.

[5] F. Blandini, "An update on the potential role of excitotoxicity in the pathogenesis of Parkinson's disease," Functional Neurology, vol. 25, no. 2, pp. 65-71, 2010.

[6] A. Tuttolomondo, R. di Sciacca, D. di Raimondo et al., "Neuron protection as a therapeutic target in acute ischemic stroke," Current Topics in Medicinal Chemistry, vol. 9, no. 14, pp. 13171334, 2009.

[7] S. J. Low and C. L. Roland, "Review of NMDA antagonistinduced neurotoxicity and implications for clinical development," International Journal of Clinical Pharmacology and Therapeutics, vol. 42, no. 1, pp. 1-14, 2004.

[8] Y. Hashimoto, T. Niikura, H. Tajima et al., "A rescue factor abolishing neuronal cell death by a wide spectrum of familial Alzheimer's disease genes and A $\beta$," Proceedings of the National Academy of Sciences of the United States of America, vol. 98, no. 11, pp. 6336-6341, 2001.

[9] Y. Hashimoto, T. Niikura, Y. Ito et al., "Detailed characterization of neuroprotection by a rescue factor humanin against 
various Alzheimer's disease-relevant insults," The Journal of Neuroscience, vol. 21, no. 23, pp. 9235-9245, 2001.

[10] T. Arakawa, A. Hirano, K. Shiraki, T. Niikura, and Y. Kita, "Advances in characterization of neuroprotective peptide, humanin," Current Medicinal Chemistry, vol. 18, no. 36, pp. 5554-5563, 2011.

[11] A. Caricasole, V. Bruno, I. Cappuccio, D. Melchiorri, A. Copani, and F. Nicoletti, "A novel rat gene encoding a Humanin-like peptide endowed with broad neuroprotective activity," The FASEB Journal, vol. 16, no. 10, pp. 1331-1333, 2002.

[12] B. Guo, D. Zhai, E. Cabezas et al., "Humanin peptide suppresses apoptosis by interfering with Bax activation," Nature, vol. 423, no. 6938, pp. 456-461, 2003.

[13] V. K. Yadav, P. Muraly, and R. Medhamurthy, "Identification of novel genes regulated by $\mathrm{LH}$ in the primate corpus luteum: insight into their regulation during the late luteal phase," Molecular Human Reproduction, vol. 10, no. 9, pp. 629-639, 2004.

[14] T. Kin, K. Sugie, M. Hirano, Y.-I. Goto, I. Nishino, and S. Ueno, "Humanin expression in skeletal muscles of patients with chronic progressive external ophthalmoplegia," Journal of Human Genetics, vol. 51, no. 6, pp. 555-558, 2006.

[15] E. Colón, M.-L. Strand, C. Carlsson-Skwirut et al., "Antiapoptotic factor humanin is expressed in the testis and prevents cell-death in Leydig cells during the first wave of spermatogenesis," Journal of Cellular Physiology, vol. 208, no. 2, pp. 373-385, 2006.

[16] S. Kariya, M. Hirano, Y. Furiya, K. Sugie, and S. Ueno, "Humanin detected in skeletal muscles of MELAS patients: a possible new therapeutic agent," Acta Neuropathologica, vol. 109, no. 4, pp. 367-372, 2005.

[17] Y. Jia, Y. H. Lue, R. Swerdloff et al., "The cytoprotective peptide humanin is induced and neutralizes Bax after pro-apoptotic stress in the rat testis," Andrology, vol. 1, no. 4, pp. 651-659, 2013.

[18] D. G. Zacharias, S. G. Kim, A. E. Massat et al., "Humanin, a cytoprotective peptide, is expressed in carotid atherosclerotic [corrected] plaques in humans," PLoS ONE, vol. 7, no. 2, Article ID e31065, 2012.

[19] T. Chiba, I. Nishimoto, S. Aiso, and M. Matsuoka, "Neuroprotection against neurodegenerative diseases: development of a novel hybrid neuroprotective peptide Colivelin," Molecular Neurobiology, vol. 35, no. 1, pp. 55-84, 2007.

[20] P. Zou, Y. Ding, Y. Sha, B. Hu, and S. Nie, "Humanin peptides block calcium influx of rat hippocampal neurons by altering fibrogenesis of A $\beta 1-40$," Peptides, vol. 24, no. 5, pp. 679-685, 2003.

[21] A. Cebere and S. Liljequist, "Ethanol differentially inhibits homoquinolinic acid- and NMDA-induced neurotoxicity in primary cultures of cerebellar granule cells," Neurochemical Research, vol. 28, no. 8, pp. 1193-1199, 2003.

[22] R. Li, M. Guo, G. Zhang, X. Xu, and Q. Li, "Neuroprotection of nicotiflorin in permanent focal cerebral ischemia and in neuronal cultures," Biological and Pharmaceutical Bulletin, vol. 29, no. 9, pp. 1868-1872, 2006.

[23] T. M. Miller and E. M. Johnson Jr., "Metabolic and genetic analyses of apoptosis in potassium/serum-deprived rat cerebellar granule cells," The Journal of Neuroscience, vol. 16, no. 23, pp. 7487-7495, 1996.

[24] J. Y. Koh and D. W. Choi, "Vulnerability of cultured cortical neurons to damage by excitotoxins: differential susceptibility of neurons containing NADPH-diaphorase," The Journal of Neuroscience, vol. 8, no. 6, pp. 2153-2163, 1988.
[25] V. Degos, T. L. Charpentier, V. Chhor et al., "Neuroprotective effects of dexmedetomidine against glutamate agonist-induced neuronal cell death are related to increased astrocyte brainderived neurotrophic factor expression," Anesthesiology, vol.118, no. 5, pp. 1123-1132, 2013.

[26] A. R. Bachar, L. Scheffer, A. S. Schroeder et al., "Humanin is expressed in human vascular walls and has a cytoprotective effect against oxidized LDL-induced oxidative stress," Cardiovascular Research, vol. 88, no. 2, pp. 360-366, 2010.

[27] Y. Hashimoto, M. Nawa, M. Kurita et al., "Secreted calmodulinlike skin protein inhibits neuronal death in cell-based Alzheimer's disease models via the heterotrimeric Humanin receptor," Cell Death \& Disease, vol. 4, article e555, 2013. 

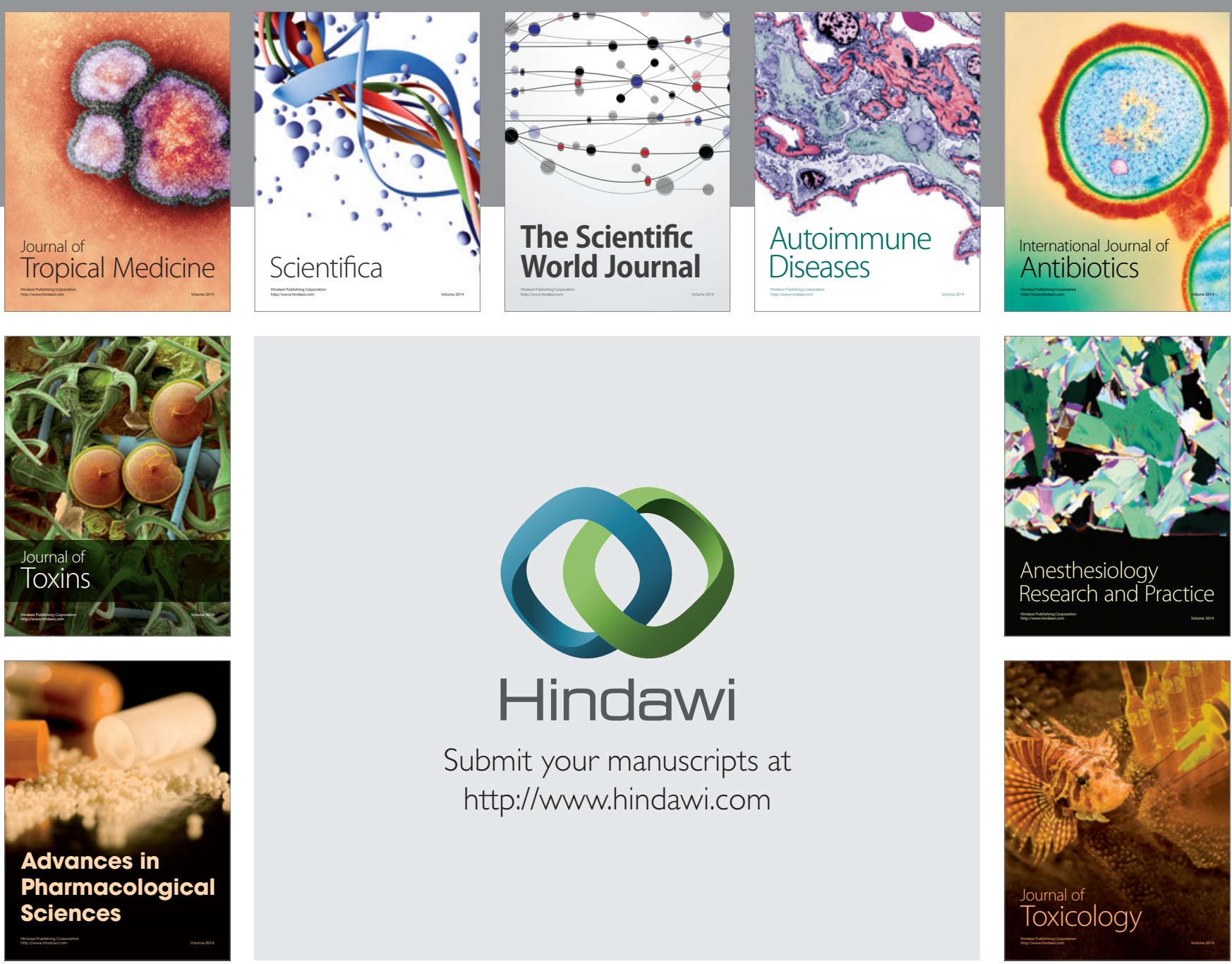

\section{Hindawi}

Submit your manuscripts at

http://www.hindawi.com
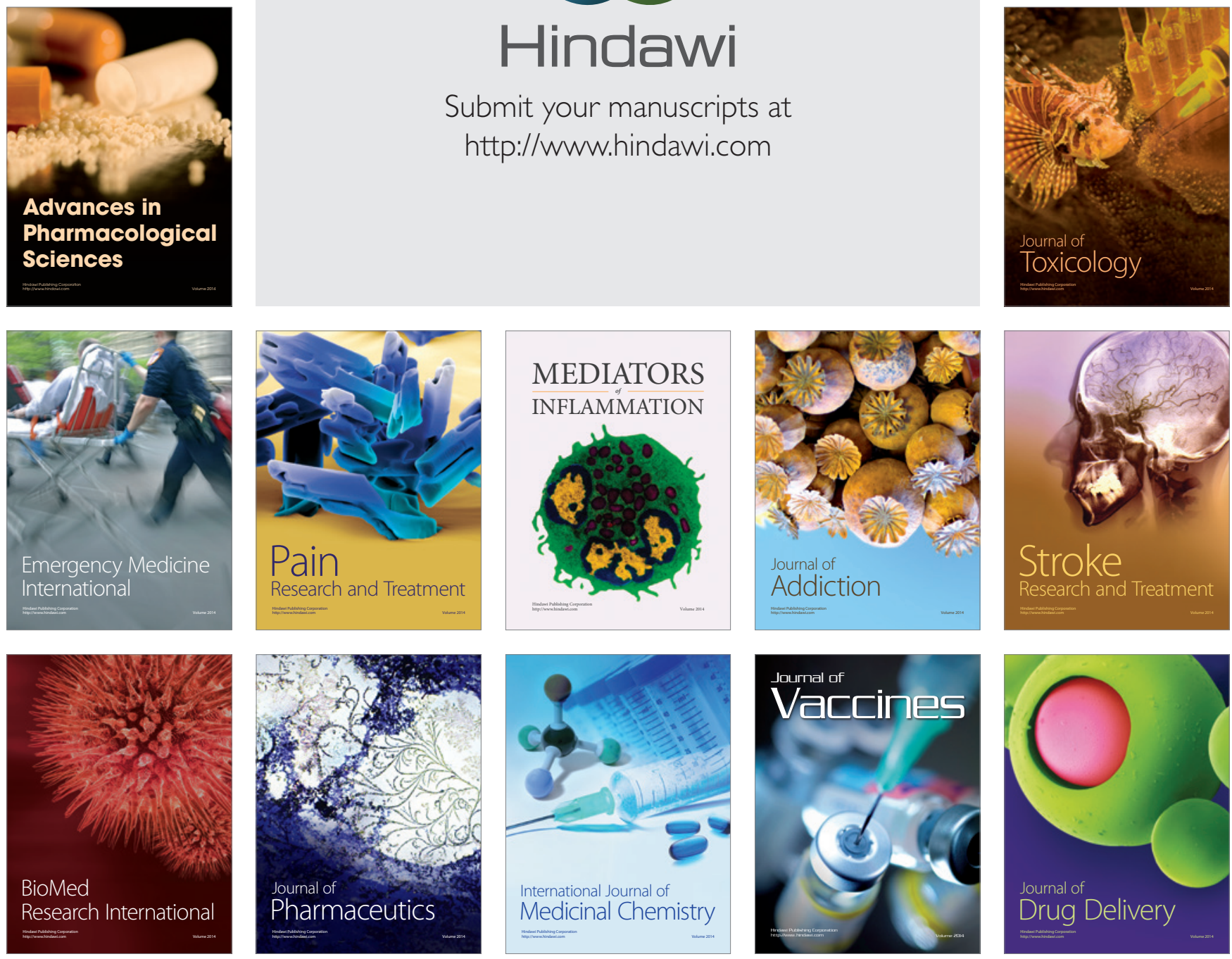